\title{
The discrimination of mirror-image forms by pigeons
}

\author{
DAVID C. TODRIN and DONALD S. BLOUGH \\ Brown University, Providence, Rhode Island
}

\begin{abstract}
Four experiments investigated the discriminability of mirror-image forms with pigeons. Experiments 1-3 used U-shaped forms, oriented up, down, right, and left. The first experiment found non-mirror images better discriminated than mirror images on a matching-to-sample task. Experiment 2 found up-down reversals better discriminated than left-right mirror images on a threekey simultaneous discrimination task. Experiment 3 replicated this result with a single stimulus presentation method on a go/no-go discrimination. The final experiment repeated Experiment 2 with F-shaped forms whose mirror images could not be produced by a 180-deg rotation, but only by a reflection about the horizontal or vertical axis. These results are consistent with most findings for human and nonhuman subjects, but contrary to a recent suggestion by Hollard and Delius (1982) that mirror-image forms are distinct for pigeons.
\end{abstract}

Many experiments have shown that simple forms may be hard to discriminate from their mirror images, and that left-right pairs (forms reflected about the vertical axis) are particularly difficult to distinguish. These findings are of more than incidental interest, for mirror-image confusion must somehow reflect the nature of underlying processes in form perception, and current models are generally inadequate to account for mirror-image confusion (see Corballis $\&$ Beale, 1976, for a review).

Confusion between left-right reflected pairs is commonly observed in humans. The frequent observation that children confuse such letters as " $d$ " and " $b$," more than " $n$ " and " $u$," when they are first learning to read and write (Smith, 1928) has been confirmed experimentally. A classic study by Rudel and Teuber (1963) demonstrated that children found left-right mirror-image $U$-shaped stimuli difficult to discriminate until age 7 , whereas up-down reversals were readily discriminated at age 3 . A number of investigations of both children and adults have subsequently confirmed this relative difficulty in discriminating left-right mirror images. These investigations have also identified several procedural variables, the most significant of which is stimulus alignment. For example, Huttenlocher (1967) found with children the typical left-right disadvantage when forms were presented side by side, but left-right pairs became relatively more discriminable when the forms were presented one above the other. However, the error

This research was supported in part by National Science Foundation Grant BNS 80-25515. We thank Patricia M. Blough for helpful comments and advice, and William F. Hayes, who wrote the program that made the figures. Parts of this manuscript were included in a Master's thesis by David C. Todrin, Brown University, 1983. D. S. Blough's mailing address is: Department of Psychology, Brown University, Providence, Rhode Island 02912. rate for left-right pairs in lateral alignment was more than twice that for up-down pairs in vertical alignment, and this relative difference has generally been supported in other studies (e.g., Sekuler \& Houlihan, 1968; Sekuler \& Rosenblith, 1964). The extent of the left-right disadvantage in humans is also somewhat affected by the use of simultaneous, rather than successive, presentations, but overall the relative difficulty of left-right mirror-image discrimination appears to be well established in humans (see Bornstein, 1982, for a review).

Although less extensively studied with nonhuman subjects, the left-right disadvantage also appears to be rather general across several species. For example, Lashley (1938) found that rats discriminated up-down U-shaped forms more accurately than left-right forms, and Sutherland (1960) obtained the same result with octopuses. Additionally, Riopelle, Rahm, Itoigawa, and Draper (1964) found that rhesus monkeys discriminated up-down mirror images of a variety of stimuli better than left-right stimuli, although performance worsened when stimulus pairs were aligned vertically (see Corballis \& Beale, 1976, for a review).

The pigeon is well suited for the study of form perception because the anatomy, physiology, and psychophysics of its visual system are relatively well documented (Donovan, 1978). Contrast sensitivity data (Nye, 1973) and visual acuity measures (P. M. Blough, 1973; Hodos, Liebowitz, \& Bonbright, 1976) indicate that the pigeon is well equipped for the perception of the stimuli used in the present research. Finally, the pigeon's perception of complex forms has been studied in several contexts (cf. Cabe, 1980). Some research with pigeons specifically addresses the problem of mirror-image confusion. Thomas, Klipec, and Lyons (1966) examined the pigeon's response characteristics for mirror-image oblique lines in a stim- 
ulus generalization task. When tested in extinction on an angularity continuum, the birds generalized more, on average, to the mirror image of the original stimulus than to intermediate values. Mello (1965, $1966 \mathrm{a}, 1966 \mathrm{~b})$ found that, under special circumstances, a mirror image may not just be confused with the original stimulus, but may be preferred to it. Pigeons trained on a 45-deg line with one eye covered responded more to a 135 -deg line than to the original stimulus when tested with the untrained eye.

Other results, however, challenge the generality of the mirror-image effect in pigeons. Meier (1971) reports evidence suggesting no differences between updown vs. left-right mirror-image discrimination in pigeons. More recently, Hollard and Delius (1982) reported that pigeons had no special difficulty discriminating mirror-image stimuli in a matching-tosample task, and suggested that mirror-image forms were "perceptually distinct" for pigeons. This conclusion raises the interesting possibility that the processes that mediate mirror-image perception in pigeons differ from those in humans and other mammals. In view of the potential importance of the mirror confusion phenomenon to our understanding of form recognition, further investigation of this problem is warranted. The present paper provides systematic evidence on the pigeon's discrimination of mirror images for two simple forms.

\section{EXPERIMENT 1}

This experiment used a modified matching-tosample procedure to evaluate differences in discriminability between mirror-image and non-mirrorimage stimuli.

\section{Method}

Subjects. Three White Carneaux pigeons were maintained at approximately $75 \%$ of their free-feeding weights by supplemental feeding (mixed grain) after each experimental session, as needed. These birds had been used in an undergraduate laboratory, where they had briefly experienced a variety of tasks unrelated to form discrimination.

Apparatus. The apparatus consisted of a subject chamber, a display screen, and an Atari 800 home computer. The subject chamber was constructed of Plexiglas and was covered by opaque paper on three sides and a black opague curtain on the fourth. The box measured $35 \mathrm{~cm}$ wide $\times 50 \mathrm{~cm}$ long $\times 45 \mathrm{~cm}$ high on the inside. In the center of the front panel was a $16-\mathrm{cm}$-square opening, $18 \mathrm{~cm}$ above the floor, for the display screen. A standard Lehigh Valley feeder was mounted behind an opening on the lower left of the front panel. The box was dark except for the light of the screen and the feeder light. The chamber was located in a sound-attenuating booth, with white masking noise delivered through a loudspeaker.

The display was produced on a small black-and-white TV monitor, with a visible screen size of $4 \times 11 \mathrm{~cm}$. The stimuli were black forms, placed $2.7 \mathrm{~cm}$ apart and $24 \mathrm{~cm}$ from the floor. The forms were contained within a 2-mm-square $5 \times 5$ dot matrix, and resembled a squared letter $U$, oriented up, down, right, or left; they subtended a visual angle of approximately $2 \mathrm{deg}$, at a distance of about 6 to $7 \mathrm{~cm}$ from the bird's eye, and were well above the bird's acuity threshold. The response keys were three glass microscope slides mounted vertically side by side on the monitor, about $10 \mathrm{~mm}$ from the screen.

The Atari computer ran the experiment, generated the stimuli, collected the data, and operated the food magazine; it was interfaced with the chamber through a relay panel.

Procedure. In pretraining, each bird was hand-shaped to eat from the food magazine and then exposed to an autoshaping procedure for 60 trials; the conditioned stimulus was a solid black 2-mm square behind the center key.

In training, the trial format was a modification of the "simultaneous matching-to-sample" procedure (Carter \& Werner, 1978). A trial began when one of the four possible stimuli appeared behind the center key. That stimulus was the "sample" for that trial, and it remained on the screen until the pigeon had pecked it (the center key) three times. The sample then disappeared for $0.25 \mathrm{sec}$, and reappeared with the target stimulus on one side and the distractor on the other side. The target for each trial was a duplicate of the sample; the distractor was the sample rotated 90,180 , or $270 \mathrm{deg}$.

Food reinforcement was scheduled according to a $10 \%$ random schedule, with the constraint that a maximum of 20 unreinforced trials could occur in sequence (excluding correction trials, correct responses within $.2 \mathrm{sec}$, and correct responses following errors).

When the bird pecked the target, the stimuli turned bright white for $1.0 \mathrm{sec}$; if, in addition, the response latency exceeded $0.20 \mathrm{sec}$ and if a food reinforcement was scheduled, the feeder light went on and the magazine operated for 2.5 to $3.5 \mathrm{sec}$, depending on the presession weight and daily intake of the bird. If a food reinforcement was not scheduled, the feeder light alone went on for $1 \mathrm{sec}$ followed by a $2-\mathrm{sec}$ intertrial interval; to discourage shortlatency responses, which appear to be under poor stimulus control (D. S. Blough, 1978), this also occurred if the response latency was less than $0.20 \mathrm{sec}$

When the bird pecked the distractor, the stimuli disappeared from the screen and the trial was repeated after a 4-sec intertrial interval. This repetition continued until the bird made the correct response, which produced a short secondary reinforcement-stimuli turned white and feeder light flashed.

The trials were presented in blocks of 24 , within which all four stimuli (up, down, right, and left) occurred six times as the sample. Each sample was paired with the three other stimuli (distractors) once on each side. Mirror-image stimulus pairs were defined as target/distractor pairs that were rotated $180 \mathrm{deg}$ (equivalent to reflection about the horizontal or vertical axis), and nonmirror pairs were 90 - or 270 -deg rotations. A full session consisted of 25 blocks ( 600 trials), but a few sessions were terminated early due to equipment failure or satiation, and of those, only sessions 10 blocks or longer were counted in the analysis.

Each bird ran for a minimum of 15 days. Stability was then evaluated, and training was terminated when the following criterion had been met: The last nine sessions were divided into threes, and criterion was met if the median percent correct scores for those three groups showed no consistent trend (up or down) and there were at least two reversals during the nine sessions (Spealman \& Gollub, 1974).

\section{Results}

Each session yielded mean percent correct scores for nonmirror (e.g., up-right or left-down) and mirror (e.g., up-down or left-right) pairs for each bird. Neither score included correction trials. Figure 1 shows the group means for each stimulus type on each session. An analysis of variance showed significantly greater accuracy for nonmirror pairs than for mirror pairs $[F(1,2)=20.71, p<.05]$, as well as a significant effect of session $[F(20,40)=4.54, p<.01]$, with no interaction. Analysis of variance on indi- 


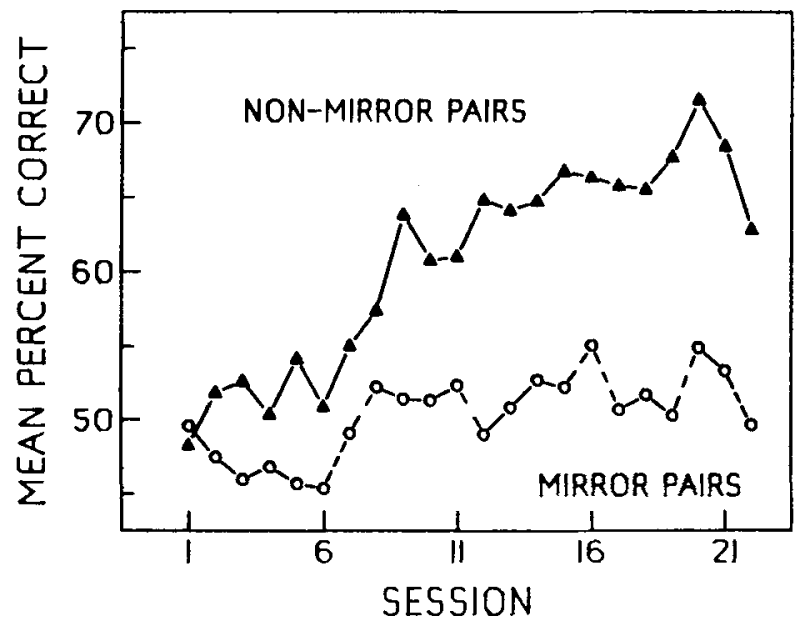

Figure 1. Mean percent correct responses for mirror and nonmirror Us in Experiment 1, averaged across all subjects. Chance performance equals $50 \%$.

vidual subject data revealed that percent correct scores for the two mirror combinations (up-down and leftright) differed neither from each other nor from chance $(50 \%)$.

\section{EXPERIMENT 2}

Experiment 1 showed that, regardless of orientation, discrimination was less accurate of mirror pairs than of nonmirror pairs. However, since both mirror pairs yielded chance performance, a floor effect may have obscured the difference between them that had been suggested by prior research. Experiment 2 compared the discriminability of up-down reversals and left-right mirror-image forms in a three-key simultaneous discrimination task that previous work (D. S. Blough, 1982) had suggested would be relatively easy for the pigeon.

\section{Method}

Subjects. This experiment used two groups of birds. Group 1 consisted of the three birds used in Experiment 1, and Group 2 consisted of three naive White Carneaux pigeons maintained as in Experiment 1.

Apparatus. The apparatus and stimuli were those used in Experiment 1.

Procedure. Group 2 was pretrained in the same manner as the Group 1 birds. Next, each bird was trained for 5 consecutive days. At the start of every session, each bird received 24 practice trials: Three stimuli appeared behind the centers of the three keys; two of them were 2-mm-square solid black stimuli (distractors), and the third (target) was one of the two positive stimuli for that bird. Three birds had "up" and "right" as positives, and three birds had "down" and "left" as positives. Each positive appeared in each of the three positions four times. After this practice block, each bird ran for 25 blocks of 24 trials each, as in Experiment 1 .

Unlike Experiment 1, this was a three-choice procedure. Each positive appeared four times in each position within each block. The mirror image of the positive on a given trial appeared behind both of the other keys on that trial. If the bird pecked at the positive, the stimuli turned white and the bird was reinforced, as de- scribed in Experiment 1. If the bird responded incorrectly, the stimuli all disappeared; the trial was repeated, but the two distractors were replaced by the 2-mm-square black blocks, and these trials continued until a correct response was made. If the bird responded with a latency of less than $0.2 \mathrm{sec}$, the screen went blank, the response was counted, and the session continued.

\section{Results}

The data for these birds were averaged, as in Experiment 1 , yielding mean percent correct scores for each stimulus type (up-down vs. left-right) per session, per bird. Figure 2 shows these data averaged across all six birds. Analysis of variance showed that up-down reversals were discriminated more accurately than left-right reversals $[F(1,5)=7.87, p<.05]$. The effect of session was also significant $[F(4,20)=$ $14.85, \mathrm{p}<.01]$, with no significant interaction; the effect of group was not significant. Median reaction times were determined for each session for correct and incorrect responses on each stimulus type, but an analysis of variance revealed no significant differences.

\section{EXPERIMENT 3}

Several researchers (see the introduction) have found that stimulus alignment affects the relative difficulty of left-right and up-down mirror discriminations. This experiment used single stimulus presentations to eliminate stimulus alignment as a variable.

\section{Method}

Subjects. Three naive White Carneaux pigeons, maintained as described in Experiment 1, were used.

Apparatus. The apparatus and stimuli were the same as those in Experiment 1, but only the center key was used.

Procedure. The birds were autoshaped as described in Experiment 1, and then each ran for 4 days. As in Experiment 2, two

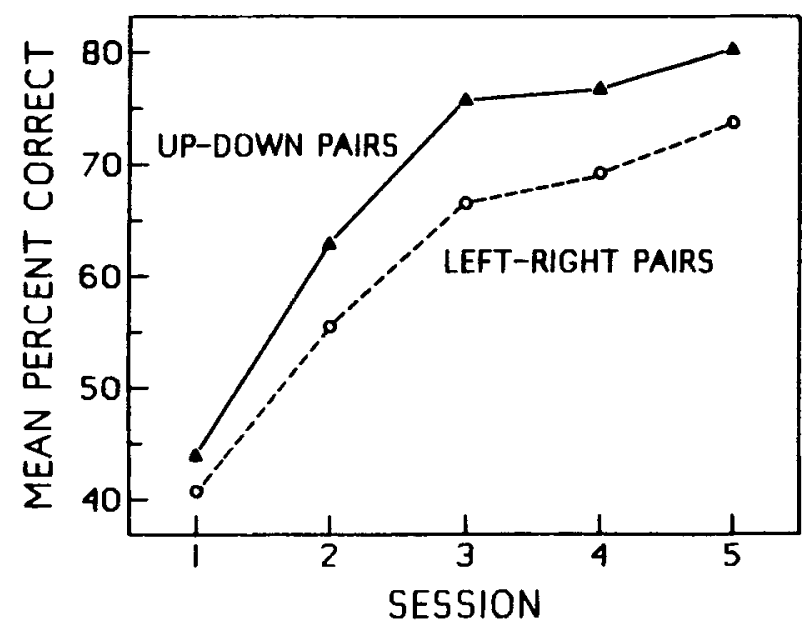

Figure 2. Mean percent correct responses for up-down and leftright Us in Experiment 2, averaged across all subjects. Chance performance equals $33.3 \%$. 
forms were positive for each bird ("up" and "right" for two birds, "down" and "left" for one), and the mirror images of these were negative. A single form appeared on each trial, centered behind the middle response key. Within each block, each of the two positives appeared four times and each of the negatives appeared 12 times in random order; this 3-to-1 ratio was used to improve discrimination. Negative stimuli remained on the screen for $2 \mathrm{sec}$, even if pecked. Positive stimuli remained on until pecked during the first two sessions; during the last two sessions, they remained on for $2 \mathrm{sec}$ or until pecked, whichever came first. On each trial, a correct response was either a peck to a positive stimulus or the withholding of all pecks to a negative stimulus; reinforcement was provided on a $50 \%$ random schedule for correct responses to a positive stimulus only.

\section{Results}

The birds responded correctly on almost all positive trials, but their percent correct scores for negative trials were substantially lower (see Figure 3). Analysis of variance confirmed the results found in Experiment 2: Up-down reversals were better discriminated than left-right reversals $[F(1,2)=25.185$, $\mathrm{p}<.05]$. Median reaction times were also recorded, both for correct responses to a positive stimulus and incorrect responses to a negative stimulus. These scores, however, were not significantly different.

\section{EXPERIMENT 4}

In the experiments above, the stimuli were bilaterally symmetric. Thus, 180-deg rotations produced stimuli identical to reflected forms. This experiment repeated Experiment 2, but used stimuli that were not bilaterally symmetric, thus distinguishing between stimulus rotation and reflection.

\section{Method}

Subjects. This experiment used two groups of birds. Group 1 consisted of three naive White Carneaux pigeons maintained as

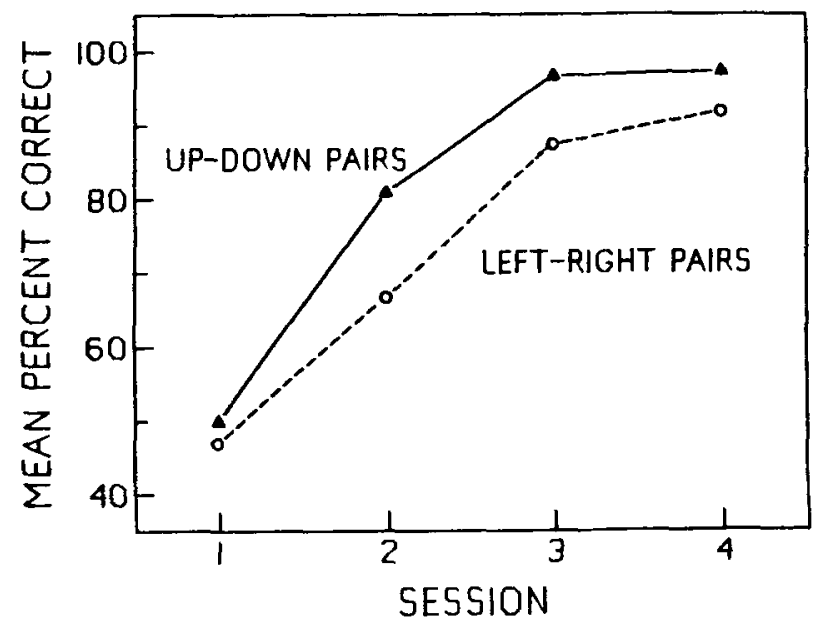

Figure 3. Mean percent correct rejections for negative trials of up-down and left-right Us in Experiment 3, averaged across all subjects. described in Experiment 1, and Group 2 consisted of the three birds used in Experiment 3.

Apparatus. The apparatus used was the same as that used in Experiment 1. The stimuli for this experiment were up-down reflections of the letter $F$ and left-right reflections of a 90 -degrotated F; the long axis of the F measured $2 \mathrm{~mm}$.

Procedure. This experiment followed the procedure used in Experiment 2, involving a three-key simultaneous discrimination task.

\section{Results}

The data for these birds were averaged as in Experiment 2 (see Figure 4). Performance on left-right pairs starts at about chance $\mathbf{3 3 . 3 \%}$ in this three-key procedure) and rises to $45 \%$ after five sessions; on up-down pairs, performance rises from $50 \%$ to $60 \%$. An analysis of variance indicated that up-down reversals were more accurately discriminated than leftright reversals $[F(1,5)=41.85, p<.01]$. The effects of session were also significant $[F(4,20)=54.7, p<$ $.01]$, with no interaction; there was no significant effect of group.

Median reaction times (for correct and incorrect responses) were recorded for each stimulus type during each session. An analysis of variance revealed no significant differences.

\section{DISCUSSION}

In these experiments, pigeons discriminated nonmirror U-shaped stimulus pairs more accurately than either up-down or left-right reversals (Experiment 1). Left-right reversals were more difficult to discriminate than up-down reversal pairs (Experiment 2). Left-right confusion did not depend on stimulus alignment (Experiment 3); it was not a discrimination of rotational cues, nor was it bound to the U-shaped form (Experiment 4).

The effects reported are unambiguous for the stimuli used here, and strongly suggest that the pigeon is similar to other species in its tendency to confuse mirror-image stimuli. Like other species, it can, of course, learn to discriminate even mirror images, as the rising curves in Figures 2-4 attest. The suggestion of Hollard and Delius (1982), that mirror-image forms are perceptually distinct for the pigeon, is based on data collected after very extensive training on mirror-image discriminations. Such training would tend to obscure the differences described here and in other species, and its outcome cannot be taken as strong evidence for processes unique to the pigeon.

Why is left-right confusion so generally found? Corballis and Beale (1976) suggest that such confusion results from evolutionary adaption to an environment that is without systematic left-right bias: Reflection about the vertical (gravitational) axis is the rule in the real world, so objects should be recognized (i.e., "confused") whether presented in left 


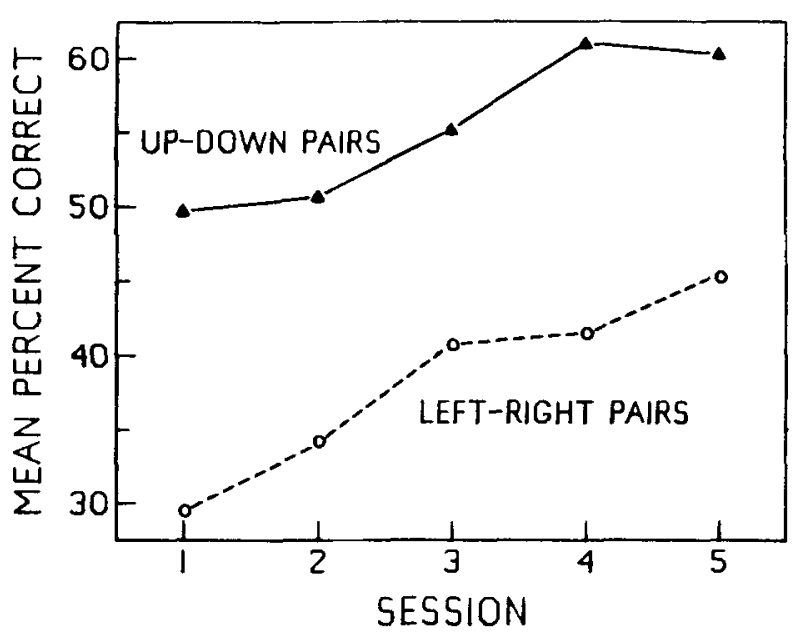

Figure 4. Mean percent correct responses for up-down and leftright $\mathrm{Fs}$ in Experiment 4 , averaged across all subjects. Chance performance equals $33.3 \%$.

or right profile. Thus, mirror-image confusion can be seen as a form of perceptual constancy.

Whether or not this adaptive argument is correct, the processes behind left-right confusion remain obscure. Corballis and Beale (1976) contended that mirror-image generalization involved higher level processes, such as memory. The idea that left-right confusion is a learned adaptation has also been suggested (e.g., Bornstein, 1982). Memory is certainly involved in the present studies, since the birds had to learn which forms were correct, and the singlestimulus experiment (Experiment 3) necessarily implicated percept-memory comparisons. Yet, reference to learning and memory comparisons has done little to clarify our understanding of the processes involved in mirror-image confusion. Several theorists have tried more direct explanations, but with limited success. Deutsch (1955) proposed that a given shape was reduced to a distribution of distances between points on its contours. Dodwell (1957), however, argued that contours were encoded by vertical and horizontal "sweeps of excitation" across a stimulus consisting of pulses and delays that varied in magnitude with the size of the contours. Thus, a shape would be coded according to the properties of its contours, irrespective of their locations. Although both of their models correctly predict left-right mirrorimage confusion, they also predict equal amounts of confusion with up-down stimulus pairs. Sutherland $(1957,1963)$ suggested that octopuses code twodimensional shapes by their horizontal and vertical projections, and that the horizontal projection is more important or salient. His model also accounts for left-right mirror-image confusion, but fails to account for the discrimination of forms that do not differ in their horizontal projections.
Corballis and Beale (1976) account for the pigeon monocular transfer results mentioned in the introduction (Mello, 1965, 1966a, 1966b) with a peripheral orientation or "beak shift" theory (Beale \& Corballis, 1968). This theory is based on the demonstration that a pigeon with one eye occluded will attend more to the half of the key facing the open eye; that is, correct responses are more likely to be located on that part of the key. Thus, in a line-tilt discrimination, monocular birds might use only those cues appearing on one half of the key. For example, a right-eyed subject would discriminate a 45-deg from a 135-deg line because the former occupied the top half of the key's right side and the latter, the bottom half. In a transfer test, the positions of the lines would appear reversed, since the bird would now attend to the left side of the key. Beale and Corballis's results showed that paradoxical transfer occurred only when the bird pecked the side of the key closer to the open eye. Thus, they interpreted Mello's results on the basis of the discrimination of top-bottom cues and not stimulus orientation and mirror-image confusion.

While plausible in the interpretation of monocular transfer data, the "beak shift" theory does not explain the binocular mirror-image confusion seen in these experiments. Furthermore, there was no distinct "side of the key," since the keys were made of clear glass with no spaces between them, and the use of small forms made it unlikely that the birds attended to only part of the stimuli.

Noble (1968) explained the confusion of left-right (vs. up-down) mirror images by postulating that each hemisphere receives both direct input and also indirect input via homotopic connections. He suggested that homotopic transfer would cause the indirect input to be reversed left to right, leading to conflict and favoring left-right confusion. This theory handles the fact that subjects can eventually learn to discriminate mirror forms by attributing greater "trace" strength to the primary visual representation. That is, with practice, the subject can learn to discriminate between the primary and reversed "traces," since the primary "trace" is stronger than the reversed "trace" that was transferred across the midline from the opposite hemisphere.

It is not clear, however, to what extent the anatomical assumptions of Noble's theory are correct (cf. Bornstein, 1982) or, if correct for primates, whether they apply to birds. Although Voneida and Mello (1975) found no evidence in the pigeon for homotopic connections between the optic tecta, Karten, Hodos, Nauta, and Revzin (1973) did find homotopic connections in the visual wulst of the owl. Further research is necessary to ascertain not only the specific nature of these interhemispheric pathways, but also their function in mediating mirror-image confusion and paradoxical transfer in pigeons. 


\section{REFERENCES}

Beale, I. L., \& Corballis, M. C. Beak shift: An explanation for interocular mirror-image reversal in pigeons. Nature, 1968, 220, 82-83.

Blovgr, D. S. Reaction times of pigeons on a wavelength discrimination task. Journal of the Experimental Analysis of Behavior, 1978, 30, 163-167.

Blovgr, D. S. Pigeon perception of letters of the alphabet. Science, 1982, 218, 397-398.

Blough, P. M. Visual acuity in the pigeon: Effects of target distance and retinal lesions. Journal of the Experimental Analysis of Behavior, 1973, 20, 333-343.

Bornste in, M. H. Perceptual anisotropies in infancy: Ontogenetic origins and implications of inequalities in spatial vision. In H. W. Reese \& L. P. Lipsitt (Eds.), Advances in child development and behavior (Vol. 16). New York: Academic Press, 1982.

CABE, P. A. Picture perception in nonhuman subjects. In $\mathbf{M}$. A. Hagen (Ed.), The perception of pictures. New York: Academic Press, 1980.

Carter, D. E., \& Werner, T. J. Complex learning and information processing by pigeons: A critical analysis. Journal of the Experimental Analysis of Behavior, 1978, 29, 565-601.

Corballis, M. C., \& Beale, I. L. The psychology of left and right. Hillsdale, N. J: Erlbaum, 1976.

DEUTsch, J. A. A theory of shape recognition. British Journal of Psychology, 1955, 46, 30-37.

DoDwelL, P. C. Shape recognition in rats. British Journal of Psychology, 1957, 48, 221-229.

Donovan, W. M. Structure and function of the pigeon visual system. Physiological Psychology, 1978, 6, 403-437.

Hodos, W., Leibowitz, R. W., \& Bonbright, J. D., JR. Nearfield visual acuity of pigeons: Effects of head location and stimulus luminance. Journal of the Experimental Analysis of Behavior, 1976, 25, 129-141.

Hollard, V. D., \& DeliUs, J. D. Rotational invariance in visual pattern recognition by pigeons and humans. Science, 1982, 218, 804-806.

HutTenlocher, J. Discrimination of figure orientation. Effects of relative position. Journal of Comparative and Physiological Psychology, 1967, 63, 359-361.

Karten, H. J., Hodos, W., Nauta, W. J. H., \& Revzin, A. M. Neural connections of the "visual wulst" of the avian telencephalon. Experimental studies in the pigeon (Columbia livia) and owl (Speotyto cunicularia). Journal of Comparative Neurology, 1973, 150, 253-278.

Lashley, K. S. The mechanism of vision, XV. Preliminary studies of the rat's capacity for detailed vision. Journal of General Psychology, 1938, 18, 123-193.

MEIER, R. E. Interhemispharischer Transfer visueller Zweifach- wahlen bei kommissurotomierten Tauben. Psychologische Forschung, 1971, 34, 220-245.

Melzo, N. K. Interhemispheric reversal of mirror-image oblique lines after monocular training in pigeons. Science, 1965, 148, 252-254.

Mello, N. K. Concerning the interhemispheric transfer of mirrorimage oblique lines after monocular training in pigeons. Physiology \& Behavior, 1966, 1, 293-300. (a)

MelLo, N. K. Interocular generalization: A study of mirror-image reversal following monocular training in pigeons. Journal of the Experimental Analysis of Behavior, 1966, 9, 11-16. (b)

Noble, J. Paradoxical interocular transfer of mirror-image discrimination in the optic chiasm sectioned monkey. Brain Research, 1968, 10, 127-151.

Nye, P. W. On the functional differences between frontal and lateral visual fields of the pigeon. Vision Research, 1973, 13, 559-574.

Riopelle, A. J., Rahm, U., Itoigawa, N., \& Draper, W. A. Discrimination of mirror-image patterns by rhesus monkeys. Perceptual and Motor Skills, 1964, 19, 383-389.

Rudel, R. G., \& Teuben, H. L. Discrimination of direction of line in children. Journal of Comparative and Physiological Psychology, 1963, 56, 892-898.

Sekulen, R. W., \& Houlihan, K. Discrimination of mirrorimages: Choice time analysis of human adult performance. Quarterly Journal of Experimental Psychology, 1968, 20, 204-207.

Sekuler, R. W., \& Rosenblith, J. F. Discrimination of direction of line and the effect of stimulus alignment. Psychonomic Science, 1964, 1, 143-144.

SMrTH, N. Matching ability as a factor in first grade reading. Journal bf Educational Psychology, 1928, 19, 560-571.

Spealman, R. D., \& Gollub, L. R. Behavioral interactions in multiple variable-interval schedules. Journal of the Experimental Analysis of Behavior, 1974, 22, 471-481.

Sutherland, N. S. Visual discrimination of orientation and shape by the octopus. Nature, 1957, 179, 11-13.

Sutherland, N. S. Visual discrimination of orientation by octopus: Mirror images. British Journal of Psychology, 1960, 51, 9-18.

Sutherland, N. S. Shape discrimination and receptive fields. Nature, 1963, 197, 118-122.

Thomas, D. R., KLipec, W., \& Lyons, J. Investigation of a mirror-image transfer effect in pigeons. Journal of the Experimental Analysis of Behavior, 1966, 9, 567-571.

Voneida, T. J., \& MELlo, N. K. Interhemispheric projections of the optic tectum in the pigeon. Brain Behavior and Evolution, 1975, 11, 91-108.

(Manuscript received January 12, 1983; revision accepted for publication July 31,1983 .) 